\title{
PENGUKURAN KUALITAS LAYANAN DALAM BIDANG PENDIDIKAN TINGGI
}

\author{
Ariesya Aprillia \\ Nonie Magdalena \\ Universitas Kristen Maranatha, Bandung \\ Email: april.lie@hotmail.com; nie_maranatha@yahoo.com
}

Submitted: Jun 13, 2018; Reviewed: Jun 15, 2018; Accepted: Jul 09, 2018

\begin{abstract}
The service industry plays an important role in a nation's economy including higher education services. The performance of the quality of higher education services is determined by the quality of service delivery provided to the students. Quality of service in education is determined by the extent to which student needs and expectations can be met. How well students will later perceive the quality of their educational services will greatly contribute to the continuity of universities in the dynamics of long-term competition. The purpose of this study was to examine and analyze how the quality of service of Maranatha Christian University is viewed from the gap between the service experienced and the expected service. The service quality measurement instrument uses seven factors: contact personnel (faculty/ lecturer), reputation, physical evidence, contact personnel (administration), curriculum, responsiveness, and access to facilities. The technique used is simple random sampling with 418 respondents. Measurement instruments are tested using validity test, reliability test, and Importance and Performance Analysis (IPA). Based on the results of data processing using IPA five things that have not been matched as expected by the student when the five things are considered important by students. These are classroom arrangement, classroom comfort, immediate announcement notice, availability of parking space, and availability of access to nonclassroom learning.
\end{abstract}

Keywords: IPA; Service Quality

\section{PENDAHULUAN}

Persaingan pada bidang pendidikan tinggi sangat ketat, tidak cukup dengan penyediaan fasilitas fisik yang baik saja, tetapi juga harus disertai proses penyelenggaraan layanan akademik yang memuaskan (Rinala, Yudana, \& Natajaya, 2013). Persaingan menjadi pemicu bagi setiap pelaku di pendidikan tinggi untuk membenahi kualitas layanannya (Abdullah, 2006a; Aprillia, Setiawan, \& Munthe, 2017). Seberapa baik nantinya mahasiswa akan memandang layanan pendidikan yang diperolehnya akan sangat berkontribusi bagi keberlangsungan perguruan tinggi dalam dinamika persaingan jangka panjang.

Performa kualitas layanan pendidikan tinggi ditentukan oleh kualitas penyampaian layanan yang diberikan kepada para pelanggannya. Internal stakeholders yang berperan penting dalam penyampaian layanan tersebut adalah tenaga pendidik serta staf tata usaha. Mereka adalah pihak yang memberikan layanan akademik dan administrasi kepada para mahasiswa sebagai external stakeholders utama pendidikan tinggi. Pelayanan Internal stakeholders di pendidikan tinggi memunyai kontribusi yang signifikan bagi penciptaan nilai kepuasan para mahasiswanya. Berkaitan dengan hal tersebut, kualitas layanan yang baik merupakan komoditi utama keunggulan bersaing di pendidikan tinggi (LeBlanc \& Nguyen, 1997; Petruzzellis, D’Uggento, \& Romanazzi, 2006; Aprillia dkk., 2017). 
Lebih dari tiga dekade terakhir ini, banyak bermunculan instrumen pengukuran untuk mengukur kualitas layanan. Antara lain Parasuraman, Zeithaml, dan Berry (1988) dengan instrumen pengukuran SERVQUALnya menjelaskan mengenai kualitas layanan (service quality) dengan membandingkan persepsi layanan yang diterima dengan harapan; Cronin dan Taylor (1992) menjelaskan mengenai SERVPERF (service performace) yang mana hanya mempertahankan mengenai persepsi kualitas layanan saja; LeBlanc dan Nguyen (1997) mengidentifikasi tujuh faktor yang memiliki dampak pada evaluasi kualitas layanan di bisnis pendidikan tinggi dan mengembangkan program untuk meningkatkan kualitas layanan agar harapan konsumen terpenuhi; serta Abdullah (2006b) mengusulkan HEdPERF (Higher Education PERFormance only), pengukuran berbasis kinerja yang mencoba menangkap faktor penentu otentik kualitas layanan di sektor pendidikan tinggi. Tidak semua hasil penelitian mengenai kualitas layanan dapat diterima oleh para peneliti lainnya, terjadi saling kritisi antara peneliti satu dengan peneliti lainnya (Abdullah, 2006a). Walaupun tidak terjadi kesepahaman yang sama di antara para peneliti, instrumen pengukuran kualitas layanan tersebut berkontribusi terhadap studi layanan dalam industri jasa, termasuk industri jasa pendidikan tinggi.

Universitas Kristen Maranatha merupakan salah satu jasa pendidikan tinggi yang ada di Indonesia. Berdasarkan penelitian yang dilakukan oleh Gunawan dan Aprillia (2015) dengan menggunakan 22 butir instrumen SERVQUAL dari Parasuraman dkk. (1988), diketahui bahwa para staf akademik dan administrasi yang melayani Fakultas Ekonomi Universitas Kristen Maranatha belum menunjukkan kualitas layanan yang memuaskan (berdasarkan persepsi mahasiswa) dalam hal kecepatan dan kenyamanan pelayanan, pemahaman dan perhatian terhadap keperluan mahasiswa, serta daya tanggap atas kebutuhan mahasiswa. Fenomena ini belum memenuhi realisasi Integrity, Care, dan Excellence sebagai nilai-nilai filosofis organisasional yang dicanangkan oleh Universitas Kristen Maranatha. Gejala ini menjadi pertanda bagi Universitas Kristen Maranatha untuk melakukan tindakan nyata dalam meningkatkan kualitas layanannya (Aprillia dkk., 2017).

Dari hasil temuan penelitian-penelitian sebelumnya, penelitian ini akan memfokuskan 12 pada instrumen pengukuran yang dikembangan oleh LeBlanc dan Nguyen (1997) yang mengidentifikasikan tujuh faktor yang memiliki dampak pada evaluasi kualitas layanan di bisnis pendidikan tinggi dan mengembangkan program untuk meningkatkan kualitas layanan agar harapan konsumen terpenuhi. Instrumen pengukuran tersebut relevan dengan keadaan pendidikan tinggi di Indonesia. Ketujuh faktor tersebut adalah contact personnel (faculty/ tenaga pendidik), reputation, physical evidence, contact personnel (administration/ staf tata usaha), curriculum, responsiveness, dan access to facilities.

\section{RUMUSAN MASALAH}

Berdasarkan latar belakang penelitian yang telah dipaparkan pada bagian sebelumnya, maka peneliti merumuskan masalah penelitian ini adalah "Bagaimana tingkat kualitas layanan Universitas Kristen Maranatha ditinjau dari kesenjangan antara layanan yang dialami dengan layanan yang diharapkan?”

\section{TUJUAN PENELITIAN}

Sejalan dengan rumusan masalah penelitian yang telah dipaparkan, maka tujuan pelaksanaan penelitian ini adalah untuk menganalisis bagaimana tingkat kualitas layanan Universitas Kristen Maranatha ditinjau dari kesenjangan antara layanan yang dialami dengan layanan yang diharapkan.

\section{TINJAUAN PUSTAKA}

Jasa memerlukan teknik pemasaran yang unik sebagai upaya untuk mencapai keunggulan bersaing (Zeithaml, Parasuraman, \& Berry, 1985) karena secara fundamental jasa berbeda dari barang. Jasa berhubungan dengan layanan. Kualitas layanan jauh lebih sukar didefinisikan, dijabarkan, dan diukur bila dibandingkan dengan kualitas barang. Menurut Parasuraman et al. (1988) kualitas layanan adalah seberapa jauh perbedaan antara kenyataan dan harapan pelanggan atas layanan yang mereka terima. Tingkat kualitas layanan tidak dapat dinilai berdasarkan sudut pandang perusahaan tetapi harus dipandang dari sudut pandang penilaian pelanggan. Persepsi kualitas layanan sering berbeda berdasarkan kebutuhan pelanggan individual (Quinn, Lemay, Larsen, \& Johnson, 2009).

Umumnya, sebagian besar peneliti mengetahui bahwa pelanggan memiliki harapan dan harapan ini berfungsi sebagai standar atau 
acuan untuk mengevaluasi kinerja sebuah organisasi. Namun, isu harapan yang belum terselesaikan sebagai penentu kualitas layanan yang dirasakan telah menghasilkan paradigma pengukuran yang saling bertentangan (Abdullah, 2006a). Dua paradigma tersebut adalah paradigma disconfirmation (SERVQUAL) dari Parasuraman dkk. (1988) yang membandingkan persepsi tentang pelayanan yang diterima dengan harapam serta persepsi paradigma (SERVPERF) dari Cronin dan Taylor (1992) yang mana hanya mempertahankan persepsi kualitas layanan. Walaupun tidak terjadi kesepahaman yang sama di antara para peneliti, instrumen pengukuran kualitas layanan tersebut berkontribusi terhadap studi layanan dalam industri jasa, termasuk industri jasa pendidikan tinggi.

Mengukur kualitas layanan di pendidikan tinggi semakin penting (LeBlanc \& Nguyen, 1997; Athiyaman, 1997; Abdullah, 2006a; Khodayari \& Khodayari, 2011; Ali, Zhou, Hussain, Nair, \& Ragavan, 2016). Meningkatkan kualitas layanan sudah dilakukan di berbagai industri termasuk industi pendidikan tinggi (Hasan, Ilias, Rahman, \& Raza, 2008; Hong, 2017). Tingkat kualitas layanan di pendidikan tinggi sangat bergantung pada jarak antara harapan dan persepsi mahasiswa terhadap layanan pendidikan tinggi. Menurut Tan dan Kek (2004) prinsip untuk meningkatkan nilai pendidikan adalah dengan berupaya terus menerus memperbaiki kualitas layanan dan fokus pada kepentingan stakeholder. Kualitas dalam pendidikan ditentukan oleh sejauhmana kebutuhan dan harapan mahasiswa dapat terpenuhi.

LeBlanc dan Nguyen (1997) mengidentifikasikan tujuh faktor yang memiliki dampak pada evaluasi kualitas layanan di bisnis pendidikan tinggi dan mengembangkan program untuk meningkatkan kualitas layanan agar harapan konsumen terpenuhi. Ketujuh faktor tersebut adalah:

1. Contact personnel (faculty/ tenaga pendidik) Terkait dengan kinerja dan kemampuan tenaga pendidik.

2. Reputation

Terkait dengan kapasitas pendidikan tinggi (universitas) untuk memosisikan dirinya di benak konsumen serta memroyeksikan citranya.

3. Physical evidence

Terkait dengan bukti fisik.

4. Contact personnel (administration/ staf tata usaha)
Terkait dengan kemampuan manajemen/ staf tata usaha untuk memberikan perhatian secara personal kepada para mahasiswanya dengan cara yang profesional dan penuh kepedulian.

5. Curriculum

Terkait dengan kemampuan faculty/ tenaga pendidik dan manajemen/ staf tata usaha untuk merencanakan dan menyampaikan layanan agar dapat memenuhi keinginan mahasiswa.

6. Responsiveness

Terkait dengan kemampuan faculty/ tenaga pendidik dan manajemen/ staf tata usaha untuk memberikan layanan secara cepat dan tepat waktu.

7. Access to facilities.

Terkait dengan kemudahan untuk mendapatkan layanan tanpa harus menunggu lama.

Berikut ini adalah beberapa penelitian terdahulu.

Tabel 1. Penelitian Terdahulu

\begin{tabular}{|c|c|c|}
\hline No. & Peneliti & Keterangan \\
\hline 1 & $\begin{array}{l}\text { Parasuraman } \\
\text { dkk. (1988) }\end{array}$ & $\begin{array}{l}\text { Penelitian ini bertujuan untuk } \\
\text { menjelaskan mengenai } \\
\text { pengembangan dari } 22 \text { butir } \\
\text { instrumen yang disebut sebagai } \\
\text { SERVQUAL untuk menilai } \\
\text { persepsi terhadap kualitas } \\
\text { layanan di organisasi jasa } \\
\text { maupun ritel. }\end{array}$ \\
\hline 2 & $\begin{array}{l}\text { Cronin \& } \\
\text { Taylor } \\
(1992)\end{array}$ & $\begin{array}{l}\text { Penelitian ini mengenai konsep } \\
\text { SERVPERF (Service } \\
\text { Performance) }\end{array}$ \\
\hline 3 & $\begin{array}{l}\text { LeBlanc \& } \\
\text { Nguyen } \\
(1997)\end{array}$ & $\begin{array}{l}\text { Penelitian ini menguji konsep } \\
\text { kualitas layanan dalam bisnis } \\
\text { pendidikan; Mengidentifikasi } \\
\text { tujuh faktor yang memengaruhi } \\
\text { evaluasi siswa terhadap } \\
\text { kualitas layanan; Tujuh faktor } \\
\text { yang memiliki dampak pada } \\
\text { evaluasi kualitas layanan di } \\
\text { bisnis pendidikan tinggi dan } \\
\text { mengembangkan program } \\
\text { untuk meningkatkan kualitas } \\
\text { layanan agar harapan } \\
\text { konsumen terpenuhi adalah: } \\
\text { contact personnel (faculty/ } \\
\text { tenaga pendidik), reputation, } \\
\text { physical evidence, contact } \\
\text { personnel (administration/ staf } \\
\text { tata usaha), curriculum, } \\
\text { responsiveness, dan access to } \\
\text { facilities. }\end{array}$ \\
\hline 4 & $\begin{array}{l}\text { Athiyaman } \\
\text { (1997) }\end{array}$ & $\begin{array}{l}\text { Penelitian ini bertujuan untuk } \\
\text { membahas dasar konseptual } \\
\text { kepuasan konsumen dan }\end{array}$ \\
\hline
\end{tabular}




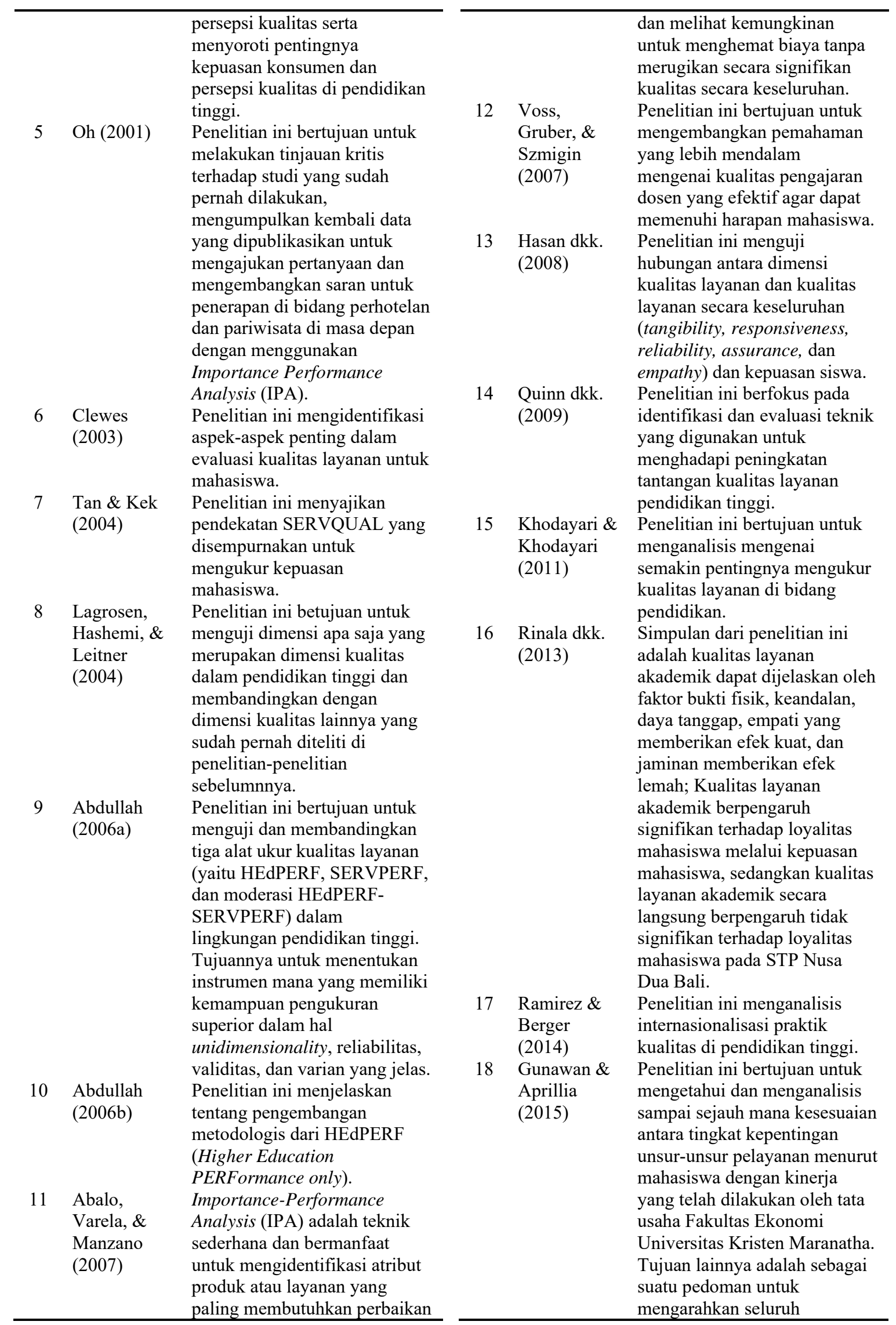




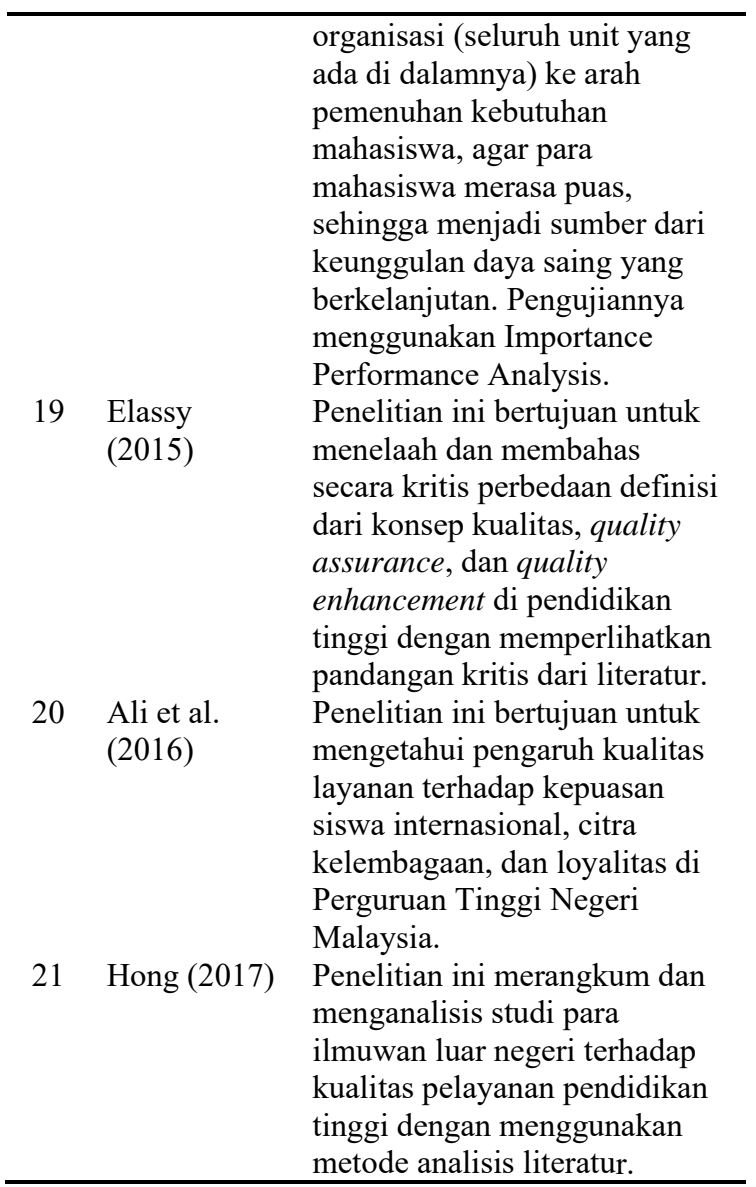

Sumber: diolah dari berbagai jurnal

Tabel 1 menunjukkan bahwa terdapat beberapa hasil penelitian dalam bidang jasa khususnya pendidikan tinggi yang pernah dilakukan dalam kurun waktu yang berkelanjutan.

\section{POPULASI DAN SAMPEL}

Populasi dalam penelitian ini adalah seluruh mahasiswa aktif Universitas Kristen Maranatha Bandung. Pengambilan sampel dalam penelitian ini menggunakan probability sampling. Teknik yang digunakan adalah simple random sampling. Sampel pada penelitian ini sebanyak 418 responden. Penelitian ini menggunakan metode survei dengan kuesioner.

\section{DEFINISI OPERASIONAL VARIABEL}

Definisi operasional variabel dalam penelitian ini yaitu contact personnel (faculty) diukur dengan 6 butir indikator, reputation diukur dengan 5 butir indikator, physical evidence diukur dengan 6 butir indikator, contact personnel (administration) diukur dengan 5 butir indikator, curriculum diukur dengan 3 butir indikator, responsiveness diukur dengan 3 butir indikator, dan access to facilities diukur dengan 3 butir indikator (LeBlanc \& Nguyen, 1997). Indikator dapat dilihat pada Tabel 5.

\section{METODE ANALISIS DATA}

Metode yang digunakan dalam menganalisis penelitian ini yaitu uji validitas, uji reliabilitas, dan Importance Performance Analysis (IPA). Pengujian validitas dalam penelitian ini dilakukan dengan cara membuat korelasi skor pada item (butir) dengan skor total itemnya. Skor item dianggap sebagai nilai $\mathrm{x}$, sedangkan skor total dianggap sebagai nilai y. Apabila skor item memiliki korelasi positif yang signifikan ( $\mathrm{r} \geq 0,5$ dengan $p$ value $\leq 0,05)$, berarti item tersebut dapat digunakan sebagai indikator untuk mengukur variabel tersebut (Hair, Anderson, Tatham, \& Black, 1998).

Hasil pengujian reliabilitas ditunjukkan oleh besarnya nilai Cronbach's alpha yang menunjukkan reliabilitas konsistensi inter item atau menguji konsistensi responden dalam menjawab seluruh item. Intrepretasi reliabilitas menurut Hair dkk. (1998), nilai Cronbach's alpha lebih besar dari 0.700 sedangkan menurut Sekaran dan Bougie (2013) yaitu nilai Cronbach's alpha kurang dari 0.600 berarti reliabilitas buruk atau kurang baik, nilai Cronbach alpha berkisar antara 0.700 sampai dengan 0.800 berarti reliabilitas dapat diterima atau baik, dan nilai Cronbach alpha lebih dari 0.800 berarti reliabilitas sangat baik.

Analisis data yang digunakan dalam penelitian ini adalah Importance and Performance Analysis (IPA). Menurut Oh (2001) serta Abalo dkk. (2007), teknik Importance and Performance Analysis dikemukakan pertama kali oleh Martilla dan James (1977). Untuk mengaplikasikan Important and Performance Analysis, kita perlu memahami konsep kualitas pelayanan yang dikembangkan oleh Parasuraman dkk. (1988). Konsep ini sebenarnya berasal dari konsep Servqual yang intinya tingkat kepentingan pelanggan (customer expectation) diukur dalam kaitannya dengan apa yang seharusnya dikerjakan oleh perusahaan agar menghasilkan produk atau jasa yang berkualitas tinggi.

Luaran dengan menggunakan IPA adalah berupa diagram kartesius dengan empat kuadran yang menunjukkan masing-masing variabel/ faktor/ atribut berada di kuadran mana. Sumbu mendatar (X) akan diisi oleh skor rerata tingkat kinerja/ kenyataan, sedangkan sumbu tegak (Y) 
akan diisi oleh skor rerata tingkat kepentingan/ harapan.

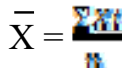

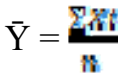

Yang mana:

$\overline{\mathrm{X}}=$ Skor rerata tingkat kinerja/ kenyataan

$\overline{\mathrm{Y}}=$ Skor rerata tingkat kepentingan/ harapan

$\mathrm{n}=$ Jumlah responden

Empat kuadran pada IPA yaitu Kuadran I menunjukkan faktor-faktor atau atribut yang penanganannya perlu diprioritaskan, Kuadran II menunjukkan faktor-faktor atau atribut yang perlu dipertahankan, karena pada umumnya tingkat pelaksanannya telah sesuai dengan kepentingan/ harapan, Kuadran III menunjukkan faktor-faktor atau atribut yang dianggap kurang penting, sedangkan kualitas kinerja/ pelaksanaannya biasa atau cukup saja, serta Kuadran IV menunjukkan faktor-faktor atau atribut yang dinilai berlebihan dalam pelaksanaannya, hal ini terutama disebabkan karena responden mengganggap tidak terlalu penting terhadap adanya faktor tersebut, akan tetapi pelaksanaannya dilakukan dengan baik.

\section{HASIL DAN PEMBAHASAN}

Pada bagian ini dijabarkan mengenai karakteristik responden, hasil uji validitas, hasil uji reliabilitas, dan hasil uji Importance Performance Analysis (IPA).

\section{Karakteristik Responden}

Berdasarkan Tabel 2 dapat dilihat karakteristik responden (418 orang responden) berdasarkan gender, fakultas dimana responden berkuliah, dan semester yang sedang ditempuh.

Tabel 2. Karakteristik Responden

\begin{tabular}{ccc}
\hline Karakteristik & Alternatif Jawaban & $\begin{array}{c}\text { Frekuensi } \\
\text { (orang) }\end{array}$ \\
\hline Gender & Pria & 175 \\
& Wanita & 243 \\
\hline Fakultas & Kedokteran & 49 \\
& Teknik & 49 \\
& Sastra & 50 \\
& Psikologi & 51 \\
& Ekonomi & 52 \\
& Seni Rupa \& Desain & 50 \\
& Teknologi Informasi & 21 \\
& Hukum & 49 \\
& Kedokteran Gigi & 47 \\
\hline
\end{tabular}

\begin{tabular}{ccc}
\hline Semester & 1 & 43 \\
& 3 & 58 \\
5 & 171 \\
& 7 & 105 \\
& 26 \\
& 11 & 10 \\
& 13 & 5 \\
\hline
\end{tabular}

Sumber: Hasil Pengolahan SPSS (2018)

\section{Hasil Uji Validitas}

Berdasarkan Tabel 3 dapat dilihat hasil uji validitas untuk variabel kepentingan/ harapan dan kinerja/ kenyataan. Semua variabel valid karena nilai $\mathrm{r}($ corr.$) \geq 0.500$ dengan $p$ value $\leq$ 0.05 .

Tabel 3. Hasil Uji Validitas Kepentingan/ Harapan \& Kinerja/ Kenyataan

\begin{tabular}{|c|c|c|c|c|c|}
\hline \multirow{2}{*}{$\begin{array}{l}\text { Variabel/ } \\
\text { Indikator }\end{array}$} & \multicolumn{2}{|c|}{$\begin{array}{c}\text { Kepentingan/ } \\
\text { Harapan }\end{array}$} & \multicolumn{2}{|c|}{$\begin{array}{c}\text { Kinerja/ } \\
\text { Kenyataan }\end{array}$} & \multirow[t]{2}{*}{ Status } \\
\hline & Corr. & Sig. & Corr. & Sig. & \\
\hline 1 & $.535^{* *}$ & 0.000 & $.545^{* *}$ & 0.000 & Valid \\
\hline 2 & $.693^{* *}$ & 0.000 & $.626^{* *}$ & 0.000 & Valid \\
\hline 3 & $.637^{* *}$ & 0.000 & $.604^{* *}$ & 0.000 & Valid \\
\hline 4 & $.721^{* *}$ & 0.000 & $.608^{* *}$ & 0.000 & Valid \\
\hline 5 & $.754^{* *}$ & 0.000 & $.602^{* *}$ & 0.000 & Valid \\
\hline 6 & $.776^{* *}$ & 0.000 & $.668^{* *}$ & 0.000 & Valid \\
\hline 7 & $.712^{* *}$ & 0.000 & $.680^{* *}$ & 0.000 & Valid \\
\hline 8 & $.781^{* *}$ & 0.000 & $.666^{* *}$ & 0.000 & Valid \\
\hline 9 & $.723^{* *}$ & 0.000 & $.683^{* *}$ & 0.000 & Valid \\
\hline 10 & $.778^{* *}$ & 0.000 & $.648^{* *}$ & 0.000 & Valid \\
\hline 11 & $.757^{* *}$ & 0.000 & $.599^{* *}$ & 0.000 & Valid \\
\hline 12 & $.779^{* *}$ & 0.000 & $.719^{* *}$ & 0.000 & Valid \\
\hline 13 & $.827^{* *}$ & 0.000 & $.683^{* *}$ & 0.000 & Valid \\
\hline 14 & $.795^{* *}$ & 0.000 & $.675^{* *}$ & 0.000 & Valid \\
\hline 15 & $.828^{* *}$ & 0.000 & $.668^{* *}$ & 0.000 & Valid \\
\hline 16 & $.827^{* *}$ & 0.000 & $.730^{* *}$ & 0.000 & Valid \\
\hline 17 & $.807^{* *}$ & 0.000 & $.696^{* *}$ & 0.000 & Valid \\
\hline 18 & $.773^{* *}$ & 0.000 & $.688^{* *}$ & 0.000 & Valid \\
\hline 19 & $.795^{* *}$ & 0.000 & $.613^{* *}$ & 0.000 & Valid \\
\hline 20 & $.769^{* *}$ & 0.000 & $.663^{* *}$ & 0.000 & Valid \\
\hline 21 & $.797^{* *}$ & 0.000 & $.673^{* *}$ & 0.000 & Valid \\
\hline 22 & $.774^{* *}$ & 0.000 & $.627^{* *}$ & 0.000 & Valid \\
\hline 23 & $.801^{* *}$ & 0.000 & $.696^{* *}$ & 0.000 & Valid \\
\hline 24 & $.766^{* *}$ & 0.000 & $.712^{* *}$ & 0.000 & Valid \\
\hline 25 & $.764^{* *}$ & 0.000 & $.662^{* *}$ & 0.000 & Valid \\
\hline 26 & $.797^{* *}$ & 0.000 & $.617^{* *}$ & 0.000 & Valid \\
\hline
\end{tabular}


Jurnal Manajemen Maranatha a Vol. 18 Nomor 1, November (2018)

\begin{tabular}{llllll}
\hline 27 & $.808^{* *}$ & 0.000 & $.651^{* *}$ & 0.000 & Valid \\
28 & $.800^{* *}$ & 0.000 & $.664^{* *}$ & 0.000 & Valid \\
29 & $.790^{* *}$ & 0.000 & $.650^{* *}$ & 0.000 & Valid \\
30 & $.794^{* *}$ & 0.000 & $.675^{* *}$ & 0.000 & Valid \\
31 & $.771^{* *}$ & 0.000 & $.629^{* *}$ & 0.000 & Valid
\end{tabular}

Sumber: Hasil Pengolahan SPSS (2018)

\section{Hasil Uji Reliabilitas}

Berdasarkan Tabel 4 dapat dilihat hasil uji reliabilitas untuk variabel kepentingan/ harapan dan kinerja/ kenyataan. Semua variabel reliabel karena nilai cronbach's alpha-nya $\geq 0.700$.

Tabel 4. Hasil Uji Reliabilitas Kepentingan/ Harapan \& Kinerja/ Kenyataan

\begin{tabular}{ccc}
\hline Variabel/ Indikator & $\begin{array}{c}\text { Cronbach's } \\
\text { alpha }\end{array}$ & Status \\
\hline Kepentingan/ Harapan & 0.976 & Reliabel \\
Kinerja/ Kenyataan & 0.955 & Reliabel \\
\hline
\end{tabular}

Sumber: Hasil Pengolahan SPSS (2018)

\section{Importance Performance Analysis}

Berdasarkan Tabel 5 dapat dilihat hasil Importance Performance Analysis.

Tabel 5. Importance Performance Analysis

\begin{tabular}{|c|c|c|c|}
\hline No. & Dimensi & $\begin{array}{c}\text { Kinerja/ } \\
\text { Kenyataan } \\
(\mathrm{X})\end{array}$ & $\begin{array}{l}\text { Kepentingan/ } \\
\text { Harapan (Y) }\end{array}$ \\
\hline \multicolumn{4}{|c|}{ Contact Personnel (Tenaga Pendidik/ Dosen) } \\
\hline 1 & $\begin{array}{l}\text { Dosen } \\
\text { berpenampilan rapi }\end{array}$ & 3.96172249 & 4.31578947 \\
\hline 2 & $\begin{array}{l}\text { Dosen bersikap } \\
\text { ramah dan sopan } \\
\text { kepada mahasiswa }\end{array}$ & 3.79186603 & 4.40191388 \\
\hline 3 & $\begin{array}{l}\text { Dosen produktif } \\
\text { dalam } \\
\text { menghasilkan } \\
\text { penelitian }\end{array}$ & 3.71770335 & 4.28708134 \\
\hline 4 & $\begin{array}{l}\text { Dosen } \\
\text { menyampaikan } \\
\text { materi perkuliahan } \\
\text { dengan } \\
\text { komunikatif }\end{array}$ & 3.75119617 & 4.35885167 \\
\hline 5 & $\begin{array}{l}\text { Dosen memiliki } \\
\text { kredibilitas } \\
\text { akademis yang baik }\end{array}$ & 3.93062201 & 4.42583732 \\
\hline 6 & $\begin{array}{l}\text { Dosen inovatif dan } \\
\text { dapat memberi } \\
\text { pengaruh positif }\end{array}$ & 3.74880383 & 4.4138756 \\
\hline \multicolumn{4}{|c|}{ Reputation } \\
\hline 7 & $\begin{array}{l}\text { Universitas Kristen } \\
\text { Maranatha (UKM) } \\
\text { selalu memberikan } \\
\text { sesuatu yang baru } \\
\text { (inovatif) }\end{array}$ & 3.4784689 & 4.35167464 \\
\hline
\end{tabular}

\begin{tabular}{|c|c|c|c|}
\hline 8 & $\begin{array}{l}\text { UKM memiliki } \\
\text { budaya organisasi, } \\
\text { kepercayaan, dan } \\
\text { value (nilai) yang } \\
\text { baik }\end{array}$ & 3.61483254 & 4.30861244 \\
\hline 9 & $\begin{array}{l}\text { UKM melakukan } \\
\text { corporate social } \\
\text { responsibility } \\
\text { (CSR) }\end{array}$ & 3.64593301 & 4.30382775 \\
\hline 10 & $\begin{array}{l}\text { UKM memiliki } \\
\text { kurikulum yang up } \\
\text { to date }\end{array}$ & 3.66028708 & 4.37799043 \\
\hline 11 & $\begin{array}{l}\text { UKM } \\
\text { mementingkan } \\
\text { kepentingan } \\
\text { mahasiswa }\end{array}$ & 3.42344498 & 4.38038278 \\
\hline \multicolumn{4}{|c|}{ Physical Evidence } \\
\hline 12 & $\begin{array}{l}\text { Tata ruang kelas } \\
\text { baik }\end{array}$ & 3.68660287 & 4.44258373 \\
\hline 13 & $\begin{array}{l}\text { Pencahayaan di } \\
\text { ruang kelas baik }\end{array}$ & 3.734450 & 4.40430622 \\
\hline 14 & $\begin{array}{l}\text { Penampilan gedung } \\
\text { baik }\end{array}$ & 3.79186603 & 4.41626794 \\
\hline 15 & $\begin{array}{l}\text { Kebersihan secara } \\
\text { keseluruhan baik }\end{array}$ & 3.74162679 & 4.42583732 \\
\hline 16 & $\begin{array}{l}\text { Ruang kelas } \\
\text { nyaman }\end{array}$ & 3.65789474 & 4.41148325 \\
\hline 17 & $\begin{array}{l}\text { Dekorasi dan } \\
\text { atmosfir baik }\end{array}$ & 3.61004785 & 4.36363636 \\
\hline \multicolumn{4}{|c|}{ Contact Personnel (Administration/ Staf Tata Usaha) } \\
\hline 18 & $\begin{array}{l}\text { Ketersediaan staf } \\
\text { tata usaha (TU) } \\
\text { mencukupi }\end{array}$ & 3.8492823 & 4.44497608 \\
\hline 19 & $\begin{array}{l}\text { Staf TU bersikap } \\
\text { ramah dan sopan } \\
\text { kepada mahasiswa }\end{array}$ & 3.77511962 & 4.42105263 \\
\hline 20 & $\begin{array}{l}\text { Staf TU memiliki } \\
\text { kemampuan untuk } \\
\text { memecahkan } \\
\text { masalah yang } \\
\text { dihadapi } \\
\text { mahasiswa }\end{array}$ & 3.75598086 & 4.4138756 \\
\hline 21 & $\begin{array}{l}\text { Staf TU memiliki } \\
\text { pengetahuan yang } \\
\text { baik tentang } \\
\text { peraturan dan } \\
\text { prosedur }\end{array}$ & 3.86124402 & 4.39952153 \\
\hline 22 & $\begin{array}{l}\text { Staf TU } \\
\text { berpenampilan rapi }\end{array}$ & 3.98325359 & 4.37559809 \\
\hline \multicolumn{4}{|c|}{ Curriculum } \\
\hline 23 & $\begin{array}{l}\text { Kurikulum sesuai } \\
\text { dengan kebutuhan } \\
\text { di dunia kerja }\end{array}$ & 3.77272727 & 4.4354067 \\
\hline 24 & $\begin{array}{l}\text { Jumlah mata kuliah } \\
\text { yang ditawarkan } \\
\text { pada setiap } \\
\text { semester sudah } \\
\text { tepat }\end{array}$ & 3.784689 & 4.31818182 \\
\hline
\end{tabular}


Jurnal Manajemen Maranatha a Vol. 18 Nomor 1, November (2018)

\begin{tabular}{|c|c|c|c|}
\hline 25 & $\begin{array}{l}\text { Isi kurikulum } \\
\text { dijelaskan dengan } \\
\text { baik kepada } \\
\text { mahasiswa (misal } \\
\text { pada saat orientasi } \\
\text { mahasiswa, } \\
\text { perwalian, dll) }\end{array}$ & 3.72488038 & 4.42344498 \\
\hline \multicolumn{4}{|c|}{ Resposiveness } \\
\hline 26 & $\begin{array}{l}\text { Mahasiswa } \\
\text { diberitahu dengan } \\
\text { segera apabila ada } \\
\text { perubahan (misal } \\
\text { tidak ada } \\
\text { perkuliahan, } \\
\text { perubahan waktu } \\
\text { ujian, perubahan } \\
\text { jadwal sidang, dll) }\end{array}$ & 3.66028708 & 4.43779904 \\
\hline 27 & $\begin{array}{l}\text { Proses pendaftaran } \\
\text { tepat waktu dan } \\
\text { bebas dari } \\
\text { kesalahan (misal } \\
\text { pendaftaran } \\
\text { pengambilan mata } \\
\text { kuliah secara } \\
\text { online, pendaftaran } \\
\text { sidang, pendaftaran } \\
\text { wisuda, dll) }\end{array}$ & 3.76555024 & 4.38995215 \\
\hline 28 & $\begin{array}{l}\text { Data disimpan } \\
\text { dengan akurat }\end{array}$ & 3.83253589 & 4.42583732 \\
\hline \multicolumn{4}{|c|}{ Access to Facilities } \\
\hline 29 & $\begin{array}{l}\text { Ketersediaan } \\
\text { tempat parkir } \\
\text { mencukupi }\end{array}$ & 3.48086124 & 4.4569378 \\
\hline 30 & $\begin{array}{l}\text { Ketersediaan akses } \\
\text { ke fasilitas } \\
\text { komputer } \\
\text { mencukupi (misal } \\
\text { ketersediaan } \\
\text { komputer di } \\
\text { perpustakaan, di } \\
\text { student lounge, dll) }\end{array}$ & 3.50956938 & 4.37799043 \\
\hline 31 & $\begin{array}{l}\text { Ketersediaan akses } \\
\text { untuk ruang belajar } \\
\text { mencukupi (misal } \\
\text { ruang belajar di } \\
\text { perpustakaan, di } \\
\text { student lounge, dll) }\end{array}$ & 3.66746411 & 4.42105263 \\
\hline
\end{tabular}

Sumber: Hasil Pengolahan SPSS (2018)

Dari hasil Importance Performance Analysis tersebut, dapat dilihat gap (kesenjangan) antara kepentingan/ harapan dengan kinerja/ kenyataan. Gap negatif apabila skor kinerja/ kenyataan lebih kecil dari kepentingan/ harapan dan gap positif apabila skor kinerja/ kenyataan lebih besar dari kepentingan/ harapan.

Berdasarkan hasil importance performance analysis dapat dibuat diagram kartesius untuk memetakan masing-masing variabel berada di posisi mana.

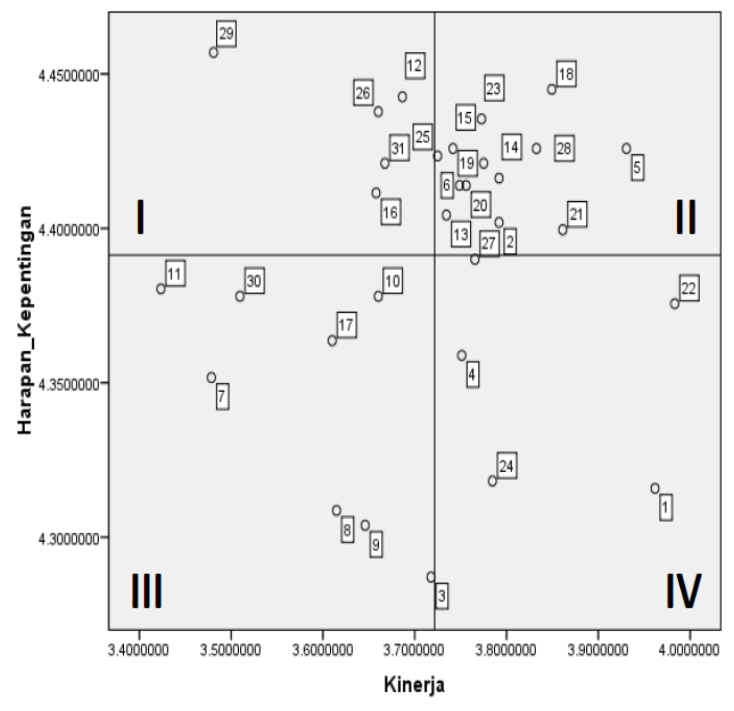

Gambar 1 Diagram Kartesius

Sumber: Hasil Pengolahan SPSS (2018)

Adapun intepretasi dari diagram kartesius tersebut dapat dijelaskan sebagai berikut.

a. Kuadran I

Menunjukkan faktor-faktor atau atribut yang penanganannya perlu diprioritaskan oleh Universitas Kristen Maranatha, karena keberadaan faktor-faktor/ atribut inilah yang dinilai sangat penting oleh mahasiswa, sedangkan tingkat kinerja/ kenyataannya masih belum memuaskan. Faktor-faktor yang termasuk dalam kuadran ini adalah:

- Penataan ruang kelas (No. 12)

- Kenyamanan ruang kelas (No. 16)

- Pemberitahuan pengumuman dengan segera (No. 26)

- Ketersediaan tempat parkir (No. 29)

- Ketersediaan akses untuk ruang belajar non kelas (No. 31)

b. Kuadran II

Menunjukkan faktor-faktor atau atribut yang perlu dipertahankan oleh Universitas Kristen Maranatha, karena pada umumnya tingkat pelaksanannya telah sesuai dengan kepentingan/ harapan mahasiswa. Faktorfaktor yang termasuk dalam kuadran ini adalah:

- Dosen bersikap ramah dan sopan kepada mahasiswa (No. 2)

- Dosen memiliki kredibilitas akademis yang baik (No. 5)

- Dosen inovatif dan dapat memberi pengaruh positif (No. 6) 
- Pencahayaan di ruang kelas baik (No. 13)

- Penampilan gedung baik (No. 14)

- Kebersihan secara keseluruhan baik (No. 15)

- Ketersediaan staf tata usaha (TU) mencukupi (No. 18)

- Staf TU bersikap ramah dan sopan kepada mahasiswa (No. 19)

- Staf TU memiliki kemampuan untuk memecahkan masalah yang dihadapi mahasiswa (No. 20)

- Staf TU memiliki pengetahuan yang baik tentang peraturan dan prosedur (No. 21)

- Kurikulum sesuai dengan kebutuhan di dunia kerja (No. 23)

- Isi kurikulum dijelaskan dengan baik kepada mahasiswa (misal pada saat orientasi mahasiswa, perwalian, dll) (No. 25)

- Data disimpan dengan akurat (No. 28)

c. Kuadran III

Menunjukkan faktor-faktor atau atribut yang dianggap kurang penting bagi mahasiswa, sedangkan kualitas kinerja/ pelaksanaannya biasa atau cukup saja. Faktor-faktor yang termasuk dalam kuadran ini adalah:

- Dosen produktif dalam menghasilkan penelitian (No. 3)

- Universitas Kristen Maranatha (UKM) selalu memberikan sesuatu yang baru (inovatif) (No. 7)

- UKM memiliki budaya organisasi, kepercayaan, dan value (nilai) yang baik (No. 8)

- UKM melakukan corporate social responsibility (CSR) (No. 9)

- UKM memiliki kurikulum yang up to date (No. 10)

- UKM mementingkan kepentingan mahasiswa (No. 11)

- Dekorasi dan atmosfir baik (No. 17)

- Ketersediaan akses ke fasilitas komputer mencukupi (misal ketersediaan komputer di perpustakaan, di student lounge, dll) (No. 30)

d. Kuadran IV

Menunjukkan faktor-faktor atau atribut yang berada dalam kuadran ini dinilai berlebihan dalam pelaksanaannya, hal ini terutama disebabkan karena mahasiswa mengganggap tidak terlalu penting terhadap adanya faktor tersebut, akan tetapi pelaksanaannya dilakukan dengan baik sekali oleh Universitas Kristen Maranatha, sehingga sangat memuaskan, akan tetapi menjadi lebih mahal. Faktorfaktor yang termasuk dalam kuadran ini adalah:

- Dosen berpenampilan rapi (No. 1)

- Dosen menyampaikan materi perkuliahan dengan komunikatif (No. 4)

- Staf tata usaha (TU) berpenampilan rapi (No. 22)

- Jumlah mata kuliah yang ditawarkan pada setiap semester sudah tepat (No. 24)

- Proses pendaftaran tepat waktu dan bebas dari kesalahan (misal pendaftaran pengambilan mata kuliah secara online, pendaftaran sidang, pendaftaran wisuda, dll) (No. 27)

\section{SIMPULAN}

Merujuk kepada hasil pengolahan data dan pembahasan, maka dapat ditarik simpulan bahwa 5 dari 31 butir indikator/ faktor/ atribut berada di Kuadran I yang mana mahasiswa merasa keberadaan faktor-faktor/ atribut inilah yang dinilai sangat penting oleh mahasiswa, sedangkan tingkat kinerja/ kenyataannya masih belum memuaskan. Mahasiswa merasa penataan ruang kelas belum optimum, misal jarak antar kursi terlalu dekat sehingga dirasa terlalu sempit; mahasiswa merasa ruang kelas belum terlalu nyaman, misal tidak adanya pendingin ruangan sehingga mahasiswa kepanasan; mahasiswa merasa bahwa pengumuman tidak diberitahukan dengan segera sehingga merugikan mahasiswa, misal pemberitahuan apabila dosen tidak ada perkuliahan dilakukan mendadak; mahasiswa merasa ketersediaan tempat parkir belum memadai, mahasiswa harus memutar berkali-kali untuk mendapatkan tempat parkir dan/atau mahasiswa harus bersedia menunggu sampai ada kendaraan yang keluar; serta yang terakhir mahasiswa merasa ketersediaan akses untuk ruang belajar non kelas tidak memadai hanya tersedia di perpustakaan dan itupun terbatas tempatnya, mahasiswa terkadang belajar di food court maupun lorong kelas.

\section{SARAN}

Saran bagi penelitian ini adalah:

1. Universitas Kristen Maranatha sebaiknya melakukan penataan ulang ruang kelas misal dengan mengurangi jumlah kursi di kelas sampai jumlah yang optimum sehingga kelas tidak terasa sesak. 
2. Universitas Kristen Maranatha sebaiknya memasang pendingin ruangan di setiap ruang kelas sehingga mahasiswa merasa nyaman dalam mengikuti proses pembelajaran.

3. Universitas Kristen Maranatha sebaiknya memberikan pengumuman dengan segera, misal menggunakan media sosial sehingga mahasiswa dapat mengetahui secepat mungkin dan dapat melihat pengumuman tersebut dari mana saja tanpa harus ke kampus terlebih dulu.

4. Universitas Kristen Maranatha sebaiknya menambah lahan parkir, misal membuat parkir basement atau membuat parkir bertingkat di depan Direktorat Kemahasiswaan.

5. Universitas Kristen Maranatha sebaiknya menyediakan ruang belajar non kelas yang memadai bagi mahasiswa, misal membuat di sekitar Direktorat Kemahasiswaan.

6. Untuk penelitian selanjutnya sebaiknya menggunakan sampling jenuh (sensus), yang mana semua anggota populasi dijadikan sebagai sampel sehingga hasilnya lebih dapat digeneralisasi dan lebih valid. Caranya dapat bekerjasama dengan direktorat ataupun badan yang ada di Univesitas Kristen Maranatha seperti BPM (Badan Penjaminan Mutu), DAA (Direktorat Administrasi Akademik, dan DI (Direktorat Informasi). Jadi mahasiswa yang akan melakukan perwalian online menggunakan SAT (Sistem Akademik Terpadu) diharuskan terlebih dahulu untuk mengisi kuesioner ini, apabila mahasiswa yang bersangkutan belum mengisi maka mahasiswa tersebut tidak bisa melakukan perwalian online dan mengakibatkan mereka terkena cuti paksa sehingga tidak dapat mengikuti perkuliahan di semester berikutnya.

\section{REFERENSI}

Abalo, J., Varela, J., \& Manzano, V. (2007). Importance Values for ImportancePerformance Analysis: A Formula for Spreading Out Values Derived From Preference Rankings. Journal of Business Research, 60, 115-121. doi:10.1016/j.jbusres.2006.10.009

Abdullah, F. (2006a). Measuring Service Quality in Higher Education: HEdPERF versus SERVPERF. Marketing Intelligence \& Planning, 24 (1), 31-47. doi: $10.1108 / 02634500610641543$
Abdullah, F. (2006b). The Development of Hedperf: A New Measuring Instrument of Service Quality for the Higher Education Sector. International Journal of Consumer Studies, 30 (6), 569-581. doi: 10.1111/j.1470-6431.2005.00480.x

Ali, F., Zhou, Y., Hussain, K., Nair, P.K., \& Ragavan, A. (2016). Does Higher Education Service Quality Effect Student Satisfaction, Image and Loyalty?: A Study of International Students in Malaysian Public Universities. Quality Assurance in Education, 24 (1), 70-94. doi: 10.1108/QAE-02-2014-0008

Aprillia, A., Setiawan, R., \& Munthe, R.G. (2017). Testing of Management Commitment as Antecendents of Prosocial Service Behavior with Job Satisfaction as Mediating Variable. International Journal of Applied Business and Economic Research, 15 (19 Part II), 511-519. Diperoleh dari $\mathrm{http}: / / \mathrm{www}$. serialsjournals.com/serialjou rnalmanager/pdf/1518168020

Athiyaman, A. (1997). Linking Student Satisfaction and Service Quality Perceptions: The Case of University Education. European Journal of Marketing, $31 \quad$ (7), 528-540. doi: 10.1108/03090569710176655

Clewes, D. (2003). A Student-centered Conceptual Model of Service Quality in Higher Education. Quality in Higher Education, 9 (1), 69-85. doi: 10.1080/1353832032000085467

Cronin, J.J. \& Taylor, S.A. (1992). Measuring Service Quality: A Reexamination and Extension. Journal of Marketing, 56 (3), 55-68. doi: 10.2307/1252296

Elassy, N. (2015). The Concepts of Quality, Quality Assurance and Quality Enhancement. Quality Assurance in Education, 23 (3), 250-261. doi: 10.1108/QAE-11-2012-0046

Gunawan, G. \& Aprillia, A. (2015). Importance and Performance Analysis (Studi Pada Tata Usaha Fakultas Ekonomi Universitas Kristen Maranatha). Proceeding Seminar Nasional Fakultas Ekonomi Universitas Kristen Maranatha. Bandung, Indonesia.

Hair, J. R., Anderson, R. E., Tatham, R. L., \& Black, W. C. (1998). Multivariate Data Analysis. $5^{\text {th }}$ Edition, Upper Saddle River, NJ: Prentice-Hall, Inc. 
Hasan, H.F.A., Ilias, A., Rahman. R.A., \& Razak, M.Z.A. (2008). Service Quality and Student Satisfaction: A Case Study at Private Higher Education Institutions. International Business Research, 1 (3), 163-175. Diperoleh dari http:// www.ccsenet.org/journal/index.php/ibr/a rticle/viewFile/982/952

Hong, C.Z. (2017). The Literature Reviews About Higher Education Service Quality in Overseas. 2nd International Conference on Education, Management and Systems Engineering (EMSE 2017). Diperoleh dari http://www.dpiproceedings.com/index.php/dtssehs/articl e/viewFile/12757/12292

Khodayari, F. \& Khodayari, B. (2011). Service Quality in Higher Education, Case Study: Measuring Service Quality of Islamic Azad University, Firoozkooh Branch. Interdisciplinary Journal of Research in Business, 1 (9), 38- 46. Diperoleh dari https://pdfs.semantic scholar.org/be34/32bc5919e7ec8315037 15a454e82894088f0.pdf

Lagrosen, S., Hashemi, R.S., \& Leitner, M. (2004). Examination of the Dimensions of Quality in Higher Education. Quality Assurance in Education, 12 (2), 61-69. doi: 10.1108/09684880410536431

LeBlanc, G. \& Nguyen, N. (1997). Searching for Excellence in Business Education: an Exploratory Study of Customer Impression of Service Quality. International Journal of Educational Management, 11 (2), 72-79. doi: $10.1108 / 09513549710163961$

Oh, H. (2001). Revisiting ImportancePerformance Analysis. Tourism Management, 22, 617-627. doi: 10.1016/S0261-5177(01)00036-X

Parasuraman, A.P., Zeithaml, V.A., \& Berry, L.L. (1988). SERVQUAL: A MultipleItem Scale for Measuring Consumer Perceptions of Service Quality. Journal of Retailing, 64 (1), 12-40. Diperoleh dari https://www.researchgate.net/ publication/225083802

Petruzzellis, L., D’Uggento, A. M., \& Romanazzi, S. (2006). Student Satisfaction and Quality of Service in Italian Universities. Managing Service Quality, 16 (4), 349-364. Diperoleh dari https:/www.researchgate.net/publication $/ 242349117$
Quinn, A., Lemay, G., Larsen, P., \& Johnson, D.M. (2009). Service Quality in Higher Education. Total Quality Management, $20 \quad$ (2), 139-152. doi: $10.1080 / 14783360802622805$

Ramirez, G.B. \& Berger, J.B. (2014). Rankings, Accreditation, and the International Quest for Quality: Organizing an Approach to Value in Higher Education. Quality Assurance in Education, 22 (1), 88-104. doi: 10.1108/QAE-07-20130031

Rinala, I.N., Yudana, I.M., \& Natajaya, I.N. (2013). Pengaruh Kualitas Pelayanan Akademik terhadap Kepuasan dan Loyalitas Mahasiswa Pada Sekolah Tinggi Pariwisata Nusa Dua Bali. eJournal Program Pascasarjana Universitas Pendidikan Ganesha Program Studi Administrasi Pendidikan, 4. Diperoleh dari hhtp://oldpasca. undiksha.ac.id/ejournal/index.php/jurnal ap/article/view/916

Sekaran, U. \& Bougie, R. (2013). Research Methods for Business: A Skill-building Approach. $6^{\text {th }}$ Edition, New York: John Wiley \& Sons Inc.

Tan, K.C. \& Kek, S.W. (2004). Service Quality in Higher Education Using an Enhanced SERVQUAL Approach. Quality in Higher Education, 10 (1), 17-24. doi: 10.1080/1353832242000195032

Voss, R., Gruber, T., \& Szmigin, I. (2007). Service Quality in Higher Education: The Role of Student Expectations. Journal of Business Research, 60, 949959. doi:10.1016/j.jbusres.2007.01.020

Zeithaml, V.A., Parasuraman, A.P., \& Berry, L.L. (1985). Problems and Strategies in Services Marketing. Journal of Marketing, 49, 33-46. Diperoleh dari https://www.researchgate.net/publication /247263456 
Jurnal Manajemen Maranatha — Vol. 18 Nomor 1, November (2018) 